УДК 550.47:571.14

\title{
МИГРАЦИЯ РТУТИ В ПОСТПИРОГЕННЫХ УСЛОВИЯХ
}

\author{
Журкова Инна Сергеевна, \\ zhurkova@igm.nsc.ru
}

Институт геологии и минералогии им. В.С. Соболева СО РАН, Россия, 630090, г. Новосибирск, пр. Ак. Коптюга, 3.

\begin{abstract}
Актуальность исследования обусловлена необходимостью оценки выноса ртути при лесных пожарах. Лесные пожары являются катализатором миграции ртути, способствуя ее активному поступлению в атмосферу. В зависимости от типа пожара соединения ртути перераспределяются в пределах пожарища или выносятся на дальние расстояния.

Цель: оценить миграцию супертоксиканта ртути в пирогенных условиях и масштабы ее воздействия на растительнье компоненты и окружающую среду.

Объекты: почва и растительные компоненты на территории Караканского бора, расположенного в Ордынском районе Новосибирской области, где произошел пожар смешанного типа, сочетающий низовой и повально-верховой.

Методы. Отбор проб почв (n=51 штук) проведен летом 2011, 2013, 2015, 2018 г2. металлическим кольцевым пробоотборником (высота 50 мм, диаметр 84 мм), используемым для экогеохимических исследований. Отбор проб коры, веток, хвои (n=15 штук) проводили ручным способом. Пробоподготовку проводили по схеме: измельчение-квартование-взвешивание. Определение ртути выполнено атомно-абсорбционным методом «холодного пара» с использованием амальгамации на золотом сорбенте. Результаты. Проведено сравнение фризико-химических характеристик проб, отобранных на фоновых и горелых территориях. Оиенено содержание ртути на фоновой и горелых поверхностях. Установлено, что содержание ртути ниже на горелых площадях, а с течением времени оно снижается как на фоновых, так и на горелых поверхностях. Рассмотрено распределение ртути в системе «кора-ветви-хвоя» для образцов, отобранных на фоновых площадях. Наименьшее содержание ртути определено в образиах хвои. Проведен анализ степени поглощения ртути растениями из почвы на примере образцов листьев березы повислой (Betula Pendula Roth) и осины обыкновенной (Pópulus trémula Linnaeus), хвои сосны обыкновенной (Pínus sylvéstris Linnaeus), иван-чая узколистного (Chamerion angustifolium Linnaeus), мхов (Hylocomium splendens Bruch), лишайников (Cladina Stellaris Opiz) на фоновой и горелой поверхностях. Наибольший коэффрициент поглощения имеет мох на фоновой $(0,75)$ и горелой $(1,0)$ поверхностях.
\end{abstract}

\section{Ключевые слова:}

Pтуть, послепожарные изменения, лесные пожары, миграция, атмосфрерное загрязнение.

\section{Введение}

Изучению лесных пожаров посвящено множество работ [1-4]. Анализ пирологических данных за последние два с лишним десятка лет (1996-2018) показывает увеличение количества лесных пожаров в различных областях Сибири [5-7]. Пожары приводят к уничтожению лесных массивов [8], изменению климата [3], заболачиванию территорий [9], загрязнению окружающий среды чему способствует вынос в атмосферу органических соединений (фосген, угарный газ, метан, фенол) $[10,11]$ тяжелых металлов [7] и радионуклидов [12]. Ранее проведены многолетние исследования миграции ряда элементов при лесных пожаpax $[13,14]$. По характеру поведения в пирогенных условиях элементы делятся на две группы: мигранты $(\mathrm{Hg}, \mathrm{Cd}, \mathrm{Pb}, \mathrm{Zn}, \mathrm{Mn}, \mathrm{As}, 90 \mathrm{Sr}, 137 \mathrm{Cs})$ и пассивные (Al, Fe, Mg, V, Cr, Ni, Co, Ca, K, Na) [7]. Перераспределение элементов приводит к изменению свойств почв [13] и элементного состава растительных компонентов [7]. Тяжелые металлы и радионуклиды оказывают токсичное действие как на растения, так и на живые организмы, более губительное влияние имеет их сочетанное действие, поскольку ионизирующее излучение и тяжелые металлы увеличивают количество аберрантных клеток в живых организмах [15]. Соединения свинца отрицательно влияют на состав крови и нервную систему, мышьяк вызывает мутагенные последствия, кадмий относится к особо опасным канцерогенам, воздействуя на многие системы организма [16-19]. Отдельная роль принадлежит ртути, относящейся к токсикантам повышенной опасности, она влияет на нервную и эндокринную системы, действует на печень, почки, кишечный тракт [20]. Ртуть легколетуча, в кислой $\mathrm{pH}$ среде образует сильные связи с серой или находится в элементарном состоянии, в водной среде образует высоко подвижные, хорошо растворимые органо-металлические соединения (метилртуть, фенилртуть) [21]. С повышением температуры и щелочности почвы ртуть поступает в атмосферу в виде паров [22]. Пары ртути ускоряют процессы старения, нарушая метаболические процессы (фотосинтез, образование хлорофилла, газового обмена, дыхания), что приводит к задержке роста всходов, развития корней и снижению урожайности, молодые растения более чувствительны к насыщенному парами ртути воздуху, чем взрослые. Скорость поглощения ртути растениями и почвенной биотой зависит от освещенности, но не зависит от температуры окружающего воздуха [23].

В настоящее время оценка естественных источников выбросов ртути считается более неопределенной, чем оценка антропогенных источников [24]. Лесные пожары способствуют активному поступлению ртути в атмосферу и ее перераспределению в ней. X. Huang et al. подсчитали [25], что среднегодовое количество выбросов ртути в результате горения биомассы составило $675 \pm 240$ т в год, что составляет $8 \%$ от общего антропогенного и природного источника ртути. 
Имеется ряд работ, посвященных миграции ртути в атмосфере, в том числе при пожарах и в постпирогенных условиях. Исследователи [26] проводили эксперимент, который заключался в сжигании образцов растительных компонентов в лабораторных условиях с целью получения зольного материала. Аналитические данные показали содержание ртути в золе меньше на 97,5-99,8 \%, чем в исходном материале, что свидетельствует о выносе ртути в атмосферу.

Настоящая работа посвящена исследованию влияния верховых пожаров на миграцию ртути. Несмотря на широкий спектр исследований, проведенных в области лесных пожаров, работы, посвященных миграции ртути немногочисленны. Учитывая ее высокую токсичность, существует необходимость в понимании ее поведения в атмосфере и влияния на растительные компоненты в условиях лесных пожаров.

Цель работы - проследить перемещение супертоксиканта ртути в пирогенных условиях и оценить масштабы ее воздействие на растительные компоненты и окружающую среду.

\section{Материалы и методы}

Объектом исследования выбраны почвы и растительные компоненты, отобранные в Караканском бору Ордынского района Новосибирской области. Караканский бор представляет собой лесостепную природную зону со множеством речек и ручьев, впадающих в Новосибирское водохранилище. Сложное геологическое строение лесного массива Караканского бора сочетает в себе рыхлый однородный материал речных террас со скальными породами различного возраста и генезиса. Здесь сосредоточены основные массивы черноземов, сформировались дерновоподзолистые почвы (боровые пески). Многие растения Караканского бора включены в региональную Красную книгу Российской Федерации [27]. Каракан включает в себя пять крупных поселений с численно- стью населения около 6 тыс. чел., а в летне-осенний период количество человек увеличивается до 15 тыс. за счет туристов [28]. Это приводит к повышенному уровню загрязнения и пожароопасной ситуации, в результате площадь бора изобилует пожарищами различного возраста.

Предметом исследования стало содержание ртути в компонентах природной среды в постпирогенных условиях в Караканском бору в мае 2006 г., образовавшихся в результате пожара, вызванного преднамеренным поджогом. Во время пожара температура воздуха составляла $26-28^{\circ} \mathrm{C}$, дул юго-западный ветер со скоростью 15-18 м/с. Тип произошедшего пожара характеризуется как смешанный, сочетающий низовой и повально-верховой с незатронутыми площадями, чему способствовали особенность рельефа бора и множество болотистых участков [29].

Обследование пожарища и прилегающих к нему площадей проведено спустя 5, 7 и 9 лет после пожара.

Отбор проб почв [30] проведен в координатных точках, указанных на рис. 1, в 16-ти точках по 3 в каждой, металлическим кольцевым пробоотборником (высота 50 мм, диаметр 84 мм), используемым при экогеохимических исследованиях [7]. Пробоотбор проходил летом 2011, 2013, 2015, 2018 гг. при ясных сухих погодных условиях, температура воздуха составляла более 20 градусов, скорость ветра не превышала 15 м/с. Масса проб составляла в среднем 80120 г. Общее количество образцов почв, листьев березы, листьев осины, хвои сосны, отобранных на фоновых и горелых поверхностях, составило 16 штук для каждого года отбора. Сухие образцы упаковывали в тряпичные продуваемые мешки. На фоновых местах в пробу попадали мхи, лишайники, свежий опад и лесная подстилка или дерновый слой почвы, т. е. все наземные лесные горючие материалы (ЛГМ), на пожарищах - все, что осталось от ЛГМ и горелая почва.

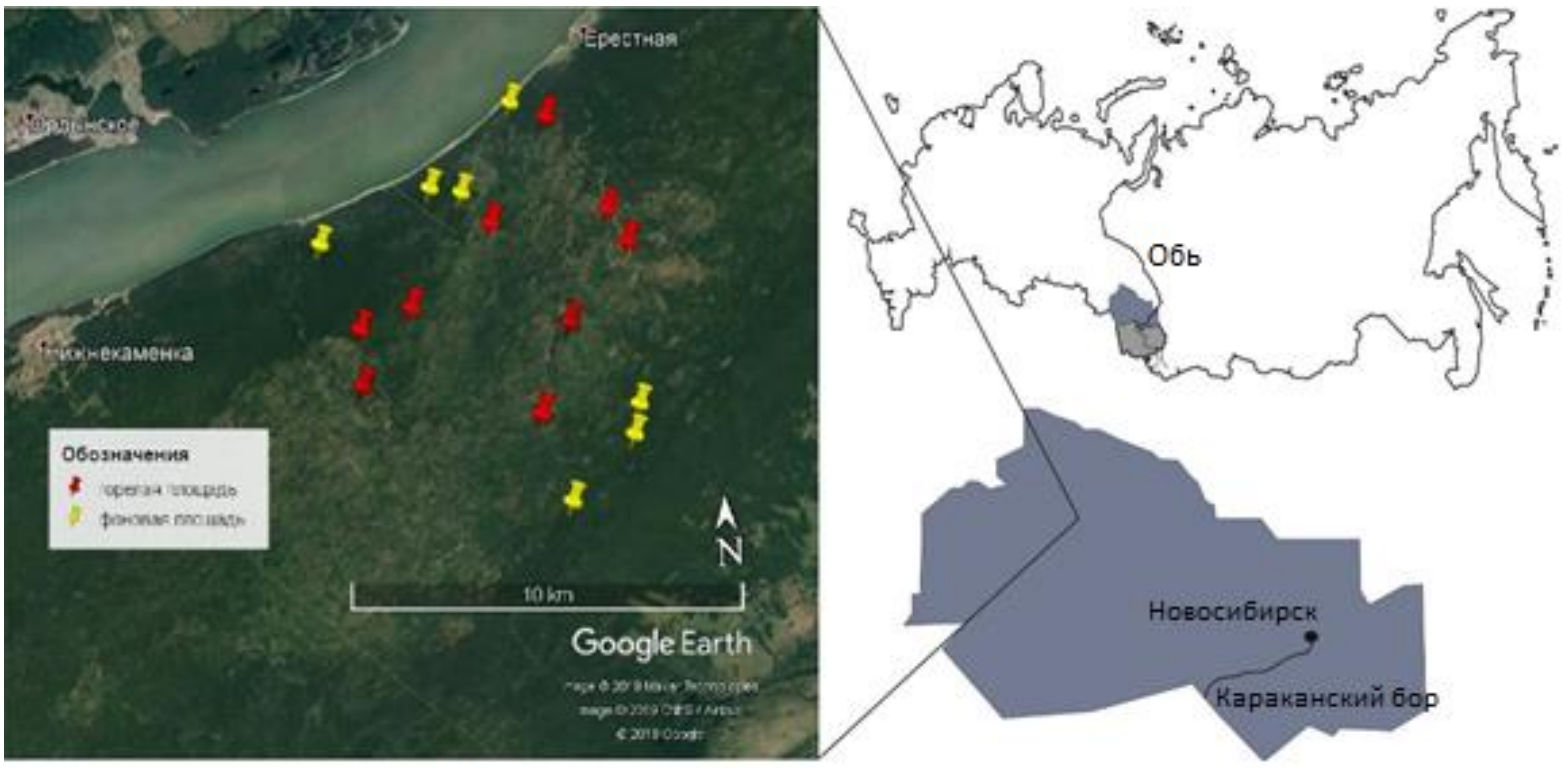

Рис. 1. Схема отбора проб. Примечание: желтые точки - фоновые площади; красные точки - горелая площадь

Fig. 1. Sampling scheme. Note: yellow points - background areas; red points - fire areas 
Отбор проб коры, веток, хвои сосны проводили вручную [7]. Возраст хвои на момент отбора составлял 1 и 3 года.

После отбора пробы высушивали и проводили стандартную подготовку (измельчение-квартованиевзвешивание) к химическому анализу [31]. Маршруты отбора проб выбирались по схеме «наветренная сторона-пожарище-подветренная сторона» для выяснения влияния пожара на геохимический состав почв пожарища и прилегающей к нему площади. Выбор расстояний между точками отбора контролировался размерами пожарища, а длина трансекта - изменением ландшафтных условий: при одинаковых параметрах достаточным считался отбор 10-12 проб за пределами гари.

Основные задачи проведенных исследований решались сравнением концентраций элементов на фоновых (прилегающих к пожарищу территориях) и выгоревших площадях.

Определение ртути выполнено атомно-абсорбционным методом «холодного пара» с использованием амальгамации на золотом сорбенте аналитиком Ж.О. Бадмаевой. Использовался спектрометр фирмы «PerkinElmer» (США), модель 3030 В с ртутно-гидридной приставкой MHS-20. Предел обнаружения метода при навеске пробы 0,5 г составляет $0,010 \pm 0,005$ ppm. Относительная погрешность составляет $10 \%$.

Аналитические работы выполнены в Центре коллективного пользования многоэлементных и изотопных исследований Института геологии и минералогии СО РАН. В фоновых и горелых почвах определена величина $\mathrm{pH}$ водных суспензий и зольность (\%). Величина $\mathrm{pH}$ определялась по опубликованной методике [32], зольность - весовым методом [33].

\section{Результаты и обсуждение}

В пробах почв подзолистого типа определены величины рН водных суспензий и зольность по опубликованным методикам. Почвы на фоновых площадях характеризуются кислой реакцией $(4,9 \pm 0,1)$ и зольностью $50 \%$, почвы на горелой поверхности - слабокислой реакцией среды $(5,7 \pm 0,2)$ и зольностью $70 \%$.

Результаты атомно-абсорбционного анализа соотносятся с данными других авторов [25, 26], сообщающих о том, что лесной пожар сопровождается выносом ртути в атмосферу, и показывают более низкое содержание ртути в образцах почвы, отобранных на горелой поверхности, чем на фоновой (рис. 2). Разница между содержанием ртути на фоновой и горелой поверхностях составила: в 2011 г. - 34,5 \%, в 2013 г. $38,7 \%$, в 2015 г. $-57,1 \%$.

Кроме того, проведенный нами мониторинг в течение нескольких лет показывает (рис. 2) снижение концентрации ртути в почвах как на фоновой, так и на горелой площадях, с увеличением времени после пожара.

Снижение концентрации ртути на фоновых площадях с течением времени связано с восстановлением катиона $\mathrm{Hg}^{2+}$ до $\mathrm{Hg}^{0}$, которое сопровождается удалением ртути из среды в виде паров, чему способствует повышение щелочности почвы [34] и температуры, которое возникает в результате солнечной активности [35].

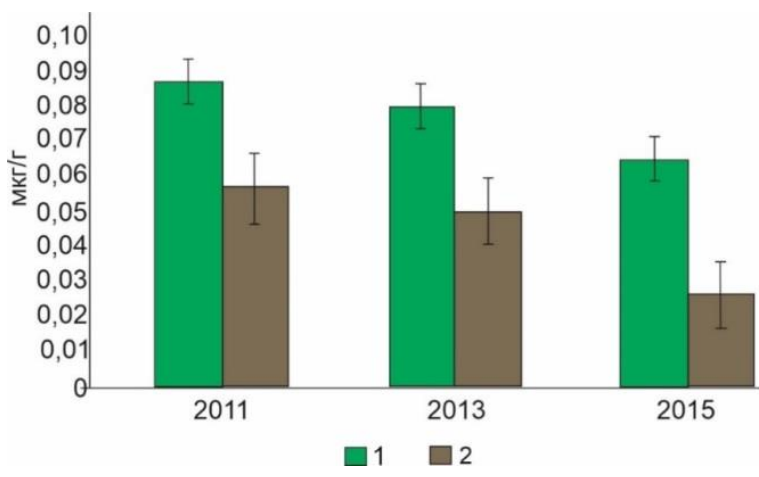

Pис. 2. Содержание ртути в почвах в зависимости от времени после пожара. Примечание: 1 - фоновая площадь ( $n=7$ в каждой выборке), 2 - горелая пломадь ( $n=9$ в каждой выборке)

Fig. 2. Mercury content in soils depending on the time after the fire. Note: 1 - background surface $(n=7$ in each sample), 2 - burned surface ( $n=9$ in each sample)

Лесной пожар сопровождается глобальным выносом в атмосферу ряда химических элементов, в частности ртути, и приводит к изменению $\mathrm{pH}$ почв в сторону щелочной $(5,7 \pm 0,2)$. В последующие годы после пожара на постпирогенных площадях происходит более активный вынос ртути в атмосферу по сравнению с фоновыми поверхностями.

Обожженные участки имеют более низкие показатели накопления ртути и сниженную способность удерживать ранее накопленные соединения ртути [36].

Исследования, проводимые на фоновой территории и территориях низового и верхового пожаров, произошедших 9 лет назад, показали различие в содержании ртути на всех рассмотренных площадях (рис. 3). Наименьшее содержание (0,03 мг/кг) отмечено в почвах, подвергшихся верховому пожару, при низовом пожаре содержание ртути составило 0,08 мг/кг, на фоновой поверхности - 0,06 мг/кг.

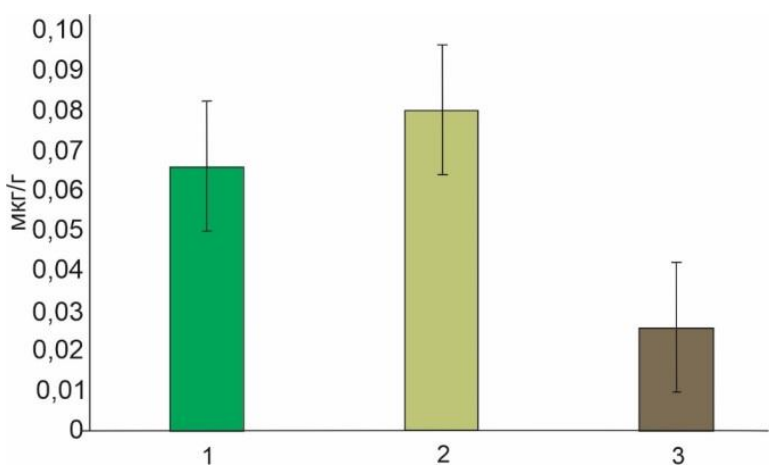

Puc. 3. Содержание ртути в почвах. Примечание: 1 фоновая площзадь $(n=7), 2$ - низовой пожар $(n=6), 3$ - верховой пожар $(n=6)$

Fig. 3. Mercury content in soils. Note: 1 -background surface $(n=7), 2-$ ground fire $(n=6), 3-$ crown fire $(n=6)$

Тип пожара влияет на распределение ртути в окружающей среде. Содержание ртути на участках 
низовых пожаров выше, чем на фоновых и верховых, поскольку, с одной стороны, при низовом пожаре ртуть перераспределяется в экосистеме, оставаясь внутри пожарища, а с другой - температура низового пожара, в отличие от температуры верхового, недостаточна для разрушения наиболее стабильных связей $\mathrm{Hg}$-лигандов [37]. Верховой пожар уничтожает практически всю лесную растительность (деревья, травы, лишайники, верхние слои почвы), сопровождаясь выносом в атмосферу химических элементов, температура кипения которых близка или ниже температуры пожара [13].

Следующий этап работы заключался в оценке распределения ртути в вегетативных органах сосны. Возраст сосен составляет 16 лет. Место их произрастания удалено от дороги и находится на территории базы отдыха «Геология» в Караканском бору. Распределение ртути смотрели в системе почва-кора-ветвихвоя. Ветви разделили на три части - возрастом более 3-х лет, менее 3-х лет и менее года.

Содержание ртути в почве, на которой произрас-

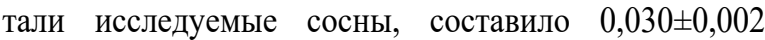
мкг/г. Наибольшее содержание ртути (рис. 4) определено в ветвях возраста более 3 -х лет $(0,040 \pm 0,004$ мкг/г). Содержание ртути в ветвях возраста менее 3 -х лет равно $0,026 \pm 0,002$ мкг $/ \Gamma$, в ветвях возраста менее года - 0,020 $\pm 0,002$ мкг/кг, в хвое возраста года отбора (мериместемные окончания) - 0,018 $\pm 0,004$ мкг/г, в коре - 0,028 мкг/г. Полученные значения концентраций ртути в почве не превышают уровень ПДК, равного 2,1 мг/кг [38].

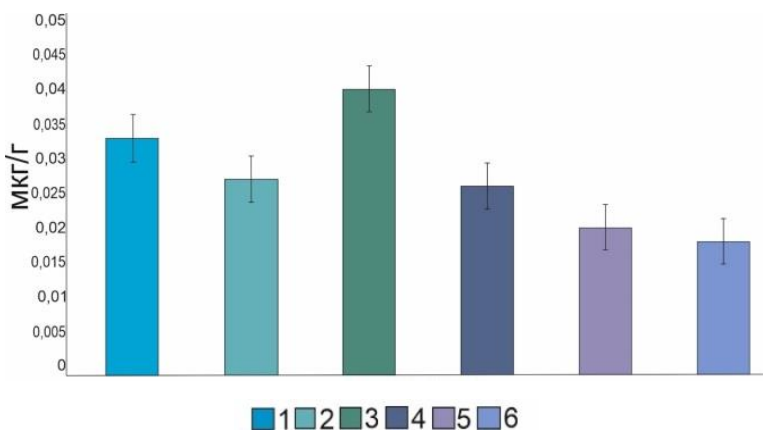

Рис. 4. Распределение ртути в органах сосны на фоновой площади. Примечание: 1 - почва, 2 - кора, 3 - ветви (возраст более3-х лет), 4 - ветви (возраст менее 3-x лет), 5 - ветви (возраст менее года), 6 -хвоя, $n=3$ для каждой выборки

Fig. 4. Mercury distribution in the organs of pine trees on a background surface. Note: 1 - soil, 2 - bark, 3 branches, 4 - young branches, 5 - new branches, 6 - pine needle, $n=3$ in each sample

Ртуть легко поглощается корневой системой и переносится в растении [35]. Однако вследствие сильного связывания ртути компонентами почвы уровень ее концентрации в самом растении может быть значительно ниже, чем в почве. Растения могут непосредственно поглощать пары ртути. Молодые растения в отличие от взрослых более чувствительны к насыщенному парами ртути воздуху [16].
По результатам полученных данных в исследуемых нами образцах органов сосны наименьшее содержание ртути определено в хвое, что подтверждает данные работы [39].

Для более детального изучения воздействия ртути на вегетативные органы растений, в зависимости от их типа и места произрастания, были рассмотрены листья березы, осины, хвоя сосны, иван-чай, лишайник, мох, отобранные на фоновых и горелых площадях. Определены содержания ртути в почвах и образцах растений, проведено сравнение содержаний на фоновой и горелой площадях, посчитаны коэффициенты концентрации для мха, лишайника и иван-чая. М. Ассад и др. проводили эксперимент по выращиванию тополей на загрязненном ртутью субстрате и в камере, обогащенной ртутью. Был сделан вывод, что листья тополя поглощают ртуть исключительно через атмосферный путь [40]. Поскольку поглощение ртути листьями березы, осины и хвоей сосны проходит путем атмосферного поступления и не зависит от содержания в почве [40], коэффициенты концентрации для них рассматривать нецелесообразно.

Коэффициент концентрации Кк характеризует степень поглощения элемента растительными компонентами из почвы, на которых они произрастают.

$$
\text { КК }=\frac{\mathrm{C} \text { (растения) }}{\mathrm{C} \text { (почвы) }}
$$

где C (растения) - содержание ртути в растении; C (почвы) - содержание ртути в почве.

Примечание: Растение -мох, иван-чай, лишайник.

Кк ртути горелых площадей выше фоновых для иван-чая, мха, лишайника. Наибольший Кк для иванчая $(0,45)$ и мха (таблица).

Таблица. Содержание (мг/кг) и коэффициенты кониентрачии ртути в почве и растениях

Table. Content $(\mathrm{mg} / \mathrm{kg})$ and mercury concentration factors in soil and plants

\begin{tabular}{|c|c|c|c|c|}
\hline \multirow{2}{*}{$\begin{array}{l}\text { Раститель- } \\
\text { ный } \\
\text { компонент } \\
\text { Vegetable } \\
\text { element }\end{array}$} & \multicolumn{2}{|c|}{$\mathrm{Hg}$} & \multicolumn{2}{|c|}{ Кк } \\
\hline & $\begin{array}{c}\text { Фон } \\
\text { Background }\end{array}$ & $\begin{array}{c}\text { Горелая } \\
\text { поверхность } \\
\text { Burned } \\
\text { surface }\end{array}$ & $\begin{array}{c}\text { Фон } \\
\text { Background }\end{array}$ & $\begin{array}{c}\text { Горелая } \\
\text { поверхность } \\
\text { Burned } \\
\text { surface }\end{array}$ \\
\hline $\begin{array}{l}\text { Почва } \\
\text { Soil }\end{array}$ & $0,080 \pm 0,010$ & $0,05 \pm 0,010$ & - & - \\
\hline $\begin{array}{l}\text { Лист березы } \\
\text { Birch leaf }\end{array}$ & $0,017 \pm 0,006$ & $0,014 \pm 0,002$ & - & - \\
\hline $\begin{array}{l}\text { Лист осины } \\
\text { Aspen leaf }\end{array}$ & $0,021 \pm 0,005$ & $0,016 \pm 0,002$ & - & - \\
\hline $\begin{array}{l}\text { Хвоя } \\
\text { Pine needle }\end{array}$ & $0,023 \pm 0,007$ & $0,014 \pm 0,002$ & - & - \\
\hline $\begin{array}{l}\text { Иван-Чай } \\
\text { Ivan-tea }\end{array}$ & $0,012 \pm 0,005$ & $0,024 \pm 0,003$ & 0,15 & 0,48 \\
\hline $\begin{array}{l}\text { Mox } \\
\text { Moss }\end{array}$ & $0,060 \pm 0,010$ & $0,050 \pm 0,01$ & 0,75 & 1,00 \\
\hline $\begin{array}{l}\text { Лишайник } \\
\text { Lichen }\end{array}$ & $0,030 \pm 0,008$ & $0,020 \pm 0,006$ & 0,37 & 0,38 \\
\hline
\end{tabular}

Коэффициент концентрации ртути зависит от типа, вегетативных органов и площади (горелая/не горелая) произрастания растений. Отсутствие корневой системы у лишайника предполагает только атмосферное поступление ртути, что делает его хорошим индикатором загрязнения окружающей среды, по 
аналогии с хвоей [39]. Кк иван-чая и мха выше на горелой поверхности, поскольку поглощение ртути происходит как из атмосферы, так и из почвы.

\section{Заключение}

Лесные пожары приводят к изменению рН почв в сторону щелочной и повышают зольность почвы на 20 \%. При низовом пожаре ртуть переносится на соседние территории, в пределах пожара. При верховом пожаре выносится в атмосферу на дальние расстояния. С каждым годом в Караканском бору концентрация ртути уменьшается как на фоновых, так и на горелых территориях, что объясняется отсутствием источника техногенного загрязнения в районе Караканского бора.

Органы сосны поглощают ртуть из почвы, большая часть ртути концентрируется во взрослых ветвях, хвоя сосны поглощает ртуть из атмосферы и служит индикатором уровня загрязнения ртутью в атмосфере.

\section{СПИСОК ЛИТЕРАТУРЬ}

1. Forest fires in Europe Middle East and North Africa / G. Schmuck, J. San-Miguel-Ayanz, A. Camia, T.H. Durrant, R. Boca G. Liberta // Reference Report by the Joint Research Center of the European Commission, 2012. - 118 p.

2. Kanga S., Tripathi G., Singh S.K. Forest fire hazards vulnerability and risk assessment in Bhaiji forest range of Himachal Pradesh (India) // Journal of Remote Sensing \& GIS. - 2017. - V. 8. № 1. - P. 1-16.

3. Valderrama L., Contreras-Reyes J., Carrasco R. Ecological impact of forest fires and subsequent restoration in Chile // Resources. 2018. - V. 7. - № 2. - P. 26-36.

4. Анализ изменения пожароопасной обстановки в лесах России в XX-XXI веках / С.П. Малевский-Малевич, Е.К. Молькентин, Е.Д. Надеждин и др. // Метеорология и гидрология. - 2007. № 3. - С. 14-24.

5. Пономарев Е.И., Харук В.Н., Якимов Н.Д. Результаты спутникового мониторинга природных пожаров Сибири // Сибирский лесной журнал. - 2017. - № 5. - С. 25-36.

6. Фуряев В.В. и др. Условия возникновения и распространения пожаров в лесных районах Красноярского края // Хвойные бореальной зоны. - 2017. - Т. 35. - № 1-2. - С. 66-74.

7. Щербов Б.Л., Лазарева Е.В., Журкова И.С. Лесные пожары и их последствия. - Новосибирск: Изд-во «ГЕО», 2015. - 154 с.

8. Condé T.M., Higuchi N., Lima A.J.N. Illegal selective logging and forest fires in the Northern Brazilian Amazon // Forests. - 2019. V. 10. - № 1. - P. 61-83.

9. Introduction to chemical engineering thermodynamics J.M. Smith, H.C. van Ness, M. Abbott, M. Swihart. - USA McGraw-Hill Education, 2018. - $768 \mathrm{p}$.

10. Маркизова Н.Ф., Преображенская Т.Н. Токсичные компоненты пожаров. - СПб: ООО Изд-во «ФОЛИАНТ», 2008. - 208 с.

11. Using low-density discrete Airborne Laser Scanning data to assess the potential carbon dioxide emission in case of a fire event in a Mediterranean pine forest / A.L. Montealegre-Gracia, M.T. Lamelas-Gracia, A. García-Martín, J. de la Riva-Fernández, F. Escribano-Bernal // GIScience \& Remote Sensing. - 2017. V. 54. - № 5. - P. 721-740.

12. Дворник А.А., Дворник А.М. Радиационная опасность продуктов сгорания горючих компонентов лесных фитоценозов // Экологический вестник. - 2015. - № 1. - С. 31-36.

13. Журкова И.С., Щербов Б.Л. Миграция химических элементов при лесном низовом пожаре (Алтайский край) // Известия Иркутского государственного университета. Серия: Науки о Земле. - 2016. - Т. 16. - С. 30-41.

14. Wright H.E., Heinselman M.L. The ecological role of fire in natural conifer forests of western and northern North America Introduction // Fire Ecology. - 2014. - V. 10. - № 3. - P. 4-13.

15. Влияние комбинированного действия ионизирующего излучения и солей тяжелых металлов на частоту хромосомных аберраций в листовой меристеме ярового ячменя / С.А. Ге-
Уровень загрязнения ртутью в исследуемой нами области Караканского бора Новосибирской области находится в пределах 0,018 $\pm 0,004$ мкг/г.

Ртуть является подвижным элементом и легко перемещается в различные ткани растений. Кк ртути для растений, произрастающих на фоновых площадях, ниже, чем Кк ртути для растений такого же вида, произрастающих на горелых площадях. Наиболее высокие значения отмечены для мха. Лишайники аналогично хвое являются индикаторами атмосферного загрязнения, поскольку не имеют корневой системы и имеют лишь атмосферный путь поступления.

Работа выполнена в рамках государственного задания № 0330-216-0011 и при финансовой поддержке гранта РФФИ в рамках научного проекта № 18-35-00408 мол_а (аналитические исследования проведены в «ЦКП Многоэлементных и изотопных анализов ИГМ СО РАН»).

раськин, В.Г. Дикарев, А.А. Удалова, Н.С. Дикарева // Генетика. - 1996. - Т. 32. - № 2. - С. 279-288.

16. Кабата-Пендиас А., Пендиас Х. Микроэлементы в почвах и растениях / Пер. с англ. - М: Мир, 1989. - 439 с.

17. Алексеенко В.А. Геохимические методы поисков месторождений полезных ископаемых. - М: Логос, 2005. - 354 с.

18. Перельман А.И., Касимов Н.С. Геохимия ландшафта. - М.: Астрея-2000, 1999. - $768 \mathrm{c}$.

19. Prevalence of exposure of heavy metals and their impact on health consequences / K. Rehman, F. Fatima, I. Waheed, M.S. Akash // Journal of cellular biochemistry. - 2018. - V. 119. - № 1. P. $157-184$

20. The toxicology of mercury: current research and emerging trends / G. Bjorklund, M. Dadar, J. Mutter, J. Aaseth // Environmental research. - 2017. - V. 159. - P. 545-554.

21. Токсичные (ртуть, бериллий) и биогенные (селен, фтор) элементы в аквальных экосистемах Байкальской природной территории / И.С. Ломоносов, В.И. Гребенщикова, О.А. Склярова, Н.Н. Брюханова, Д.А. Носков, Л.М. Яновский, Ю.Н. Диденков // Водные ресурсы. - 2011. - Т. 38. - № 2. - С. 193-204.

22. Hightower J. Methyl mercury reference dose: response to Schoen // Environmental Health Perspectives. - 2004. - V. 112. - № 6. - P. 337-338.

23. Subir M., Ariya P.A., Dastoor A.P. A review of the sources of uncertainties in atmospheric mercury modeling II. Mercury surface and heterogeneous chemistry - a missing link // Atmospheric Environment. - 2012. - V. 46. - P. 1-10.

24. New constraints on terrestrial surface-atmosphere fluxes of gaseous elemental mercury using a global database / Y. Agnan, T. Le Dantec, C.W. Moore, G.C. Edwards, D. Obrist // Environ. Sci. Technol - 2016. - V. 50 - P. 507-524.

25. Mercury emissions from biomass burning in China / X. Huang, M. Li, H.R. Friedli, Y. Song, D. Chang, L. Zhu // Environ. Sci. Technol. - 2011. - V. 45 (21). - P. 9442-9448.

26. Friedl H.R., Radkem L.F., Lu J.Y. Mercury in smoke from biomass fires // Geophysical research letters. - 2001. - V. 28. № 17. - P. 3223-3226.

27. Красная книга Российской Федерации (Растения и грибы) / под ред. Ю.П. Трутнева, Р.Р. Гизатулина, О.Л. Митволь. - М.: ООО Товарищество научных изданий КМК, 2008. - 885 c.

28. Грицкевич О.В., Ушакова Е.О. Развитие рекреационного потенциала территории на примере Караканского бора Ордынского района Новосибирской области // Интерэкспо ГеоСибирь. - 2015. - Т. 3. - № 1. - С. 46-51.

29. Журкова И.С., Щербов Б.Л., Будашкина В.В. Постпирогенный элементный состав почвенно-растительного покрова в сосновом бору (Новосибирская область) // Вестник воронежского университета. Серия: География. Геоэкология. - 2018. № 3. - C. 44-49.

30. ГОСТ 17.4.4.02.2017 Почвы. Методы отбора и подготовки проб для химического, бактериологического, гельминтологического анализа. - М.: Стандартинформ, 2018. - 21 с. 
31. ГОСТ Р 56157-2014 Почва. Методики (методы) анализа состава и свойств проб почв. Общие требования к разработке. - М.: Стандартинформ, 2015. - $10 \mathrm{c}$.

32. Пустовалов Л.В., Соколова Е.И. Методы определения $\mathrm{pH}$ и Eh в осадочных породах // Методы изучения осадочных пород. 1957. - T. 2. - C. 116-127.

33. Аринушкина Е.В. Руководство по химическому анализу почв. - М.: Изд-во Московского университета, 1961. - 488 с.

34. Lin C.J., Pehkonen S.O. The chemistry of atmospheric mercury: a review // Atmospheric environment. - 1999. - V. 33. - № 13. P. 2067-2079.

35. Grigal D.F. Mercury sequestration in forests and peatlands // Journal of environmental quality. - 2003. - V. 32. - № 2. P. 393-405.

36. Release of mercury from Rocky Mountain forest fires / A. Biswas, J.D. Blum, B. Klaue, G.J. Keeler // Global Biogeochemical Cycles. - 2007. - V. 21. - № 1. - P. 1-13.
37. Effects of wildfire on mercury mobilisation in eucalypt and pine forests / I. Campos, C. Vale, N. Abrantes, J.J. Keizer, P. Pereira // Catena. - 2015. - V. 131. - P. 149-159.

38. Арефьева А.С., Барыгина В.В., Зацепина О.В. Современные представления о влиянии соединений ртути на клеточном и системном уровне (обзор) // Экология человека. - 2010. № 8. - C. 35-41.

39. Factors influencing mercury uptake by leaves of stone pine (Pinus pinea L.) in Almadén (Central Spain) / J.I. Barquero, S. Rojas, J.M. Esbrí, E.M. García-Noguero P. Higueras // Environmental Science and Pollution Research. - 2017. - V. 24. - P. 3129-3137.

40. Mercury uptake into poplar leaves / M. Assad, J. Parelle, D. Cazaux, F. Gimbert, M. Chalot, F. Tatin-Froux // Chemosphere. - 2016. - № 146. - P. 1-7.

Поступила 22.02.2020 г.

\section{Информация об авторах}

Журкова И.С., младший научный сотрудник Института геологии и минералогии им. В.С. Соболева СО РАН. 
UDC 550.47:571.14

\title{
MERCURY MIGRATION IN POST-FIRE CONDITIONS
}

\author{
Inna S. Zhurkova, \\ zhurkova@igm.nsc.ru \\ V.S. Sobolev Institute of Geology and Mineralogy SB RAS, \\ 3, Academic Koptyug avenue, Novosibirsk, 630090, Russia.
}

The relevance of the research is caused by the need to assess mercury removal during forest fires. Forest fires are a catalyst for mercury migration, contributing to its active entry into the atmosphere. Mercury compounds are redistributed within the conflagration or carried over long distances, depending on the type of fire.

The main aim of the research is to assess mercury supertoxicant movement in pyrogenic conditions and the extent of its impact on plant components and the environment.

Objects: territory of the Karakansky boron, located in the Ordinsky district of the Novosibirsk region, where there was a mixed-type fire combining ground fire and general fire.

Methods. Soil samples were taken with a steel ring (height $50 \mathrm{~mm}$, diameter $84 \mathrm{~mm}$ ) used in ecogeochemical studies. Sampling of bark, branches, needles was conducted by hand. Sample preparation was carried out according to the scheme «grinding-quartering-weighing». Mercury was determined by the atomic absorption method of «cold steam» using amalgamation on a gold sorbent.

Results. The author has compared the physicochemical characteristics of the samples taken from background and burnt areas and evaluated mercury content on background and burnt surfaces. It is established that mercury content is lower on the burnt areas, and over time it decreases both on the background and on the burnt surfaces. Mercury distribution in the system "bark-branches-needles» for samples taken from background areas, was studied. The lowest mercury content is determined in needles samples. The degree of mercury absorption by plants from the soil was analyzed by the example of birch and aspen leaves, needles, Ivan tea, mosses, and lichens on the background and burnt surfaces. Moss on the background $(0,75)$ and burnt $(1,0)$ surfaces has the highest absorption coefficient.

\section{Key words:}

Mercury, post-fire changes, forest fires, migration, atmospheric pollution.

The work was performed within the framework of the state assignment No. 0330-216-0011 and with the financial support of the RFBR grant in the framework of the scientific project No. 18-35-00408 mol_a (analytical studies were conducted in the Center for Multiple Element and Isotopic Analyzes of the IGM SB RAS).

\section{REFERENCES}

1. Schmuck G., San-Miguel-Ayanz J., Camia A., Durrant T.H., Boca R., Liberta G. Forest fires in Europe Middle East and North Africa. Reference Report by the Joint Research Center of the European Commission, 2012.118 p.

2. Kanga S., Tripathi G., Singh S.K. Forest fire hazards vulnerability and risk assessment in Bhajji forest range of Himachal Pradesh (India). Journal of Remote Sensing \& GIS, 2017, vol. 8, no. 1 , pp. 1-16.

3. Valderrama L., Contreras-Reyes J., Carrasco R. Ecological impact of forest fires and subsequent restoration in Chile. Resources, 2018, vol. 7, no. 2, pp. 26-36.

4. Malevsky-Malevich S.P., Molkentin E.K., Nadezhdin E.D. Analysis of changes in the fire hazard situation in the forests of Russia in the XX-XXI centuries. Meteorology and hydrology, 2007, no. 3, pp. 14-24. In Rus.

5. Ponomarev E.I., Kharuk V.N., Yakimov N.D. Results of satellite monitoring of wildfires of Siberia. Siberian Forest Journal, 2017, no. 5, pp. 25-36. In Rus.

6. Furyaev V.V. Conditions for the occurrence and spread of fires in forest areas of the Krasnoyarsk Territory. Coniferous boreal zone, 2017, vol. 35, no. 1-2, pp. 66-74. In Rus.

7. Shcherbov B. L., Lazareva E. V., Zhurkova I. S. Lesnye pozhary $i$ $i k h$ posledstviya [Forest fires and their consequence]. Novosibirsk, GEO Publ., 2015. $154 \mathrm{p}$

8. Conde T. M., Higuchi N., Lima J.N.A. Illegal selective logging and forest fires in the Northern Brazilian Amazon. Forests, 2019, vol. 10, no. 1, pp. 61-83.

9. Smith J.M., Van Ness H.C., Abbott M., Swihart M. Introduction to chemical engineering thermodynamics. USA, McGraw-Hill Education, 2018. $768 \mathrm{p}$.

10. Markizova N.F., Preobrazhenskaya T.N. Toksichnye komponenty pozharov [Toxic components of fires]. St-petersburg, FOLIANT Publ., 2008. 208 p.
11. Lamelas-Gracia A.L., Garcia-Martin M.T., Riva-Fernandez A., Escribano-Bernal J.F. Using low-density discrete Airborne Laser Scanning data to assess the potential carbon dioxide emission in case of a fire event in a Mediterranean pine forest MontealegreGracia. GIScience \& Remote Sensing, 2017, vol. 54, no. 5, pp. 721-740.

12. Dvornik A.A., Dvornik A.M. Radiation hazard of combustion products of combustible components of forest phytocenose. Ecological bulletin, 2015, no. 1, pp. 31-36. In Rus.

13. Zhurkova I.S., Shcherbov B.L. Migration of chemical elements in forest ground fire (Altai Territory). News of the Irkutsk State University. Series: Earth Sciences, 2016, vol. 16, pp. 30-41. In Rus.

14. Wright H.E., Heinselman M.L. The ecological role of fire in natural conifer forests of western and northern North America. Fire Ecology, 2014, vol. 10, no. 3, pp. 4-13.

15. Geraskin S.A., Dikarev V.G., Udalova A.A., Dikareva N.S. Effect of the combined effect of ionizing radiation and heavy metal salts on the frequency of chromosomal aberrations in spring barley leaf meristem. Genetics, 1996, vol. 32, no. 2, pp. 279-288. In Rus.

16. Kabata-Pendias A., Pendias H. Mikroelementy $v$ pochvakh $i$ rasteniyakh [Trace elements in soils and plant]. Moscow, Mir Publ., 1989. 439 p.

17. Alekseenko V.A. Geokhimicheskie metody poiskov mestorozhdeniy poleznykh iskopaemykh [Geochemical methods of prospecting mineral deposits]. Moscow, Logo Publ., 2005. 354 p.

18. Perelman A.I., Kasimov N.S. Geokhimiya landshafta [Landscape geochemistry]. Moscow, Astre Publ., 2000. 768 p.

19. Rehman K., Fatima F., Waheed I., Akash M. S. Prevalence of exposure of heavy metals and their impact on health consequences. Journal of cellular biochemistry, 2018, vol. 11, no. 91, pp. $157-184$.

20. Dadar G., Mutter M., Aaseth J. The toxicology of mercury: Current research and emerging trends. Bjorklund. Environmental research, 2017, vol. 159, pp. 545-554. 
21. Lomonosov I.S., Grebenshchikova V.I., Sklyarova O.A. Toxic (mercury, beryllium) and biogenic (selenium, fluorine) elements in aquatic ecosystems of the Baikal natural territory. Water resources, 2011, vol. 38, no. 2, pp. 193-204. In Rus.

22. Hightower J. Methyl mercury reference dose: response to Schoen Environmental Health Perspectives, 2004, vol. 112, no. 6, pp. 337-338.

23. Subir M., Ariya P.A., Dastoor A.P. A review of the sources of uncertainties in atmospheric mercury modeling II. Mercury surface and heterogeneous chemistry - a missing link. Atmospheric Environment, 2012, vol. 46, pp. 1-10.

24. Agnan Y., Le Dantec T., Moore C.W., Edwards G.C., Obrist D. New constraints on terrestrial surface-atmosphere fluxes of gaseous elemental mercury using a global database. Environmental Science Technology, 2016, vol. 50, pp. 507-524.

25. Huang X., Li M., Friedli H.R., Song Y., Chang D., Zhu L. Mercury emissions from biomass burning in China. Environmental Science Technology, 2011, vol. 45, no. 21, pp. 9442-9448.

26. Friedl H.R., Radke L.F., Lu J.Y. Mercury in smoke from biomass fires. Geophysical research letters, 2001, vol. 28, no. 17, pp. 3223-3226.

27. Krasnaya kniga Rossiyskoy Federatsii (Rasteniya i griby) [Red Book of the Russian Federation (Plants and Mushrooms]. Eds. Yu.P. Trutnev, R.R. Gizatulin, O.L. Mitvol. Moscow, KMK Publ., 2008. $885 \mathrm{p}$.

28. Grickevich O.V., Ushakova E.O. Development of the recreational potential of the territory on the example of Karakansky pine forest, Orda district, Novosibirsk region. Interexpo Geo-Siberia, 2015, vol. 3, no. 1, pp. 46-51. In Rus.

29. Zhurkova I.S., Shcherbov B.L., Budashkina V.V. Post-pyrogenic elemental composition of so il and plant cover in a pine forest (Novosibirsk region). Bulletin of the Voronezh University. Series: Geography. Geoecology, 2018, no. 3, pp. 44-49. In Rus.

30. GOST 17.4.4.02.2017 Pochvy. Metody otbora i podgotovki prob dlya khimicheskogo, bakteriologicheskogo, gelmintologicheskogo analiza [SS 17.4.4.02.2017 Soils. Methods of sample selection and preparation for chemical bacterial and helminthological analysis]. Moscow, Standardinform Publ., 2018. 21 p.

31. GOST 56157-2014 Pochva. Metodiki, metody analiza sostava $i$ svoystv prob pochv. Obshchie trebovaniya $k$ razrabotke [SS 56157-2014 Soil. Methods and techniques of composition and features of soil samples. General requirements to development]. Moscow, Standardinform Publ., 2015. 10 p.

32. Pustovalov L.V., Sokolova E.I. Metody opredeleniya $\mathrm{pH}$ i Eh v osadochnykh porodakh [Methods for determining $\mathrm{pH}$ and $\mathrm{Eh}$ in sedimentary rocks]. Metody izucheniya osadochnykh porod, 1957, vol. 2, pp. 116-127.

33. Arinushkina E.V. Rukovodstvo po khimicheskomu analizu pochv [Manual on chemical analysis of soil]. Moscow, Moscow University Press, 1961.488 p.

34. Lin C.J., Pehkonen S.O. The chemistry of atmospheric mercury: a review. Atmospheric environment, 1999, vol. 33, no. 13, pp. 2067-2079.

35. Grigal D.F. Mercury sequestration in forests and peatlands. Journal of environmental quality, 2003, vol. 32, no. 2, pp. 393-405.

36. Biswas A., Blum J.D., Klaue B., Keeler G.J. Release of mercury from Rocky Mountain forest fires. Global Biogeochemical Cycles, 2007, vol. 21, no. 1, pp. 1-13.

37. Campos I., Vale C., Abrantes N., Keizer J.J., Pereira P. Effects of wildfire on mercury mobilisation in eucalypt and pine forests. Catena, 2015, vol. 131, pp. 149-159.

38. Arefeva A.S., Barygina V.V., Zacepina O.V. Current views on the effects of mercury compounds at the cellular and systemic levels (review). Human ecology, 2010, no. 8, pp. 35-41. In Rus.

39. Barquero J.I., Rojas S., Esbri J.M., García-Noguero E.M. Higueras $\mathrm{P}$. Factors influencing mercury uptake by leaves of stone pine (Pinus pinea L.) in Almaden (Central Spain). Environmental Science and Pollution Research, 2017, vol. 24, pp. 3129-3137.

40. Assad M., Parelle J., Cazaux D., Gimbert F., Chalot M., TatinFroux F. Mercury uptake into poplar leaves. Chemosphere, 2016, no. 146, pp. 1-7.

Received: 22 February 2020.

\section{Information about the authors}

Inna S. Zhurkova, junior researcher, V.S. Sobolev Institute of Geology and Mineralogy SB RAS. 